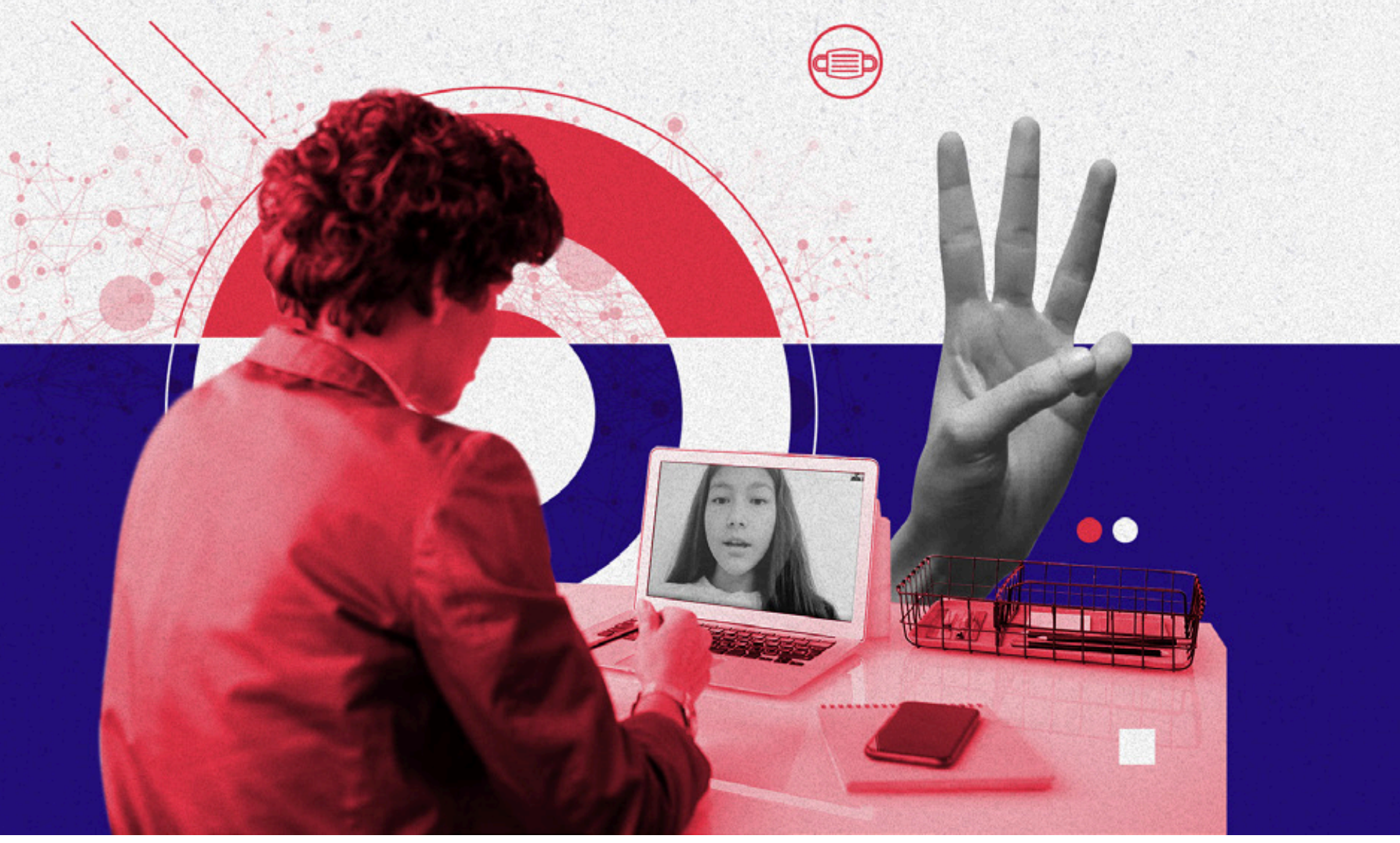

\title{
La escuela, un puente desbordado por el torrente de la pandemia
}

THE SCHOOL, A BRIDGE OVERFLOWED BY THE PANDEMIC'S STREAM A ESCOLA, UMA PONTE TRANSBORDADA PELA TORRENTE DA PANDEMIA José Israel González Blanco ${ }^{1}$ 
Citar artículo como:

González-Blanco, J.I. (2021). La escuela, un puente desbordado por el torrente de la pandemia. Educación y Ciudad, n. 41, pp. 57-69. https://doi.org/10.36737/01230425.n41.2021.2531

Fecha de recepción: 11 de abril de 2021

Fecha de aprobación: 6 de julio de 2021

\section{Resumen}

El documento es una reflexión sobre la escuela desde una analogía de esta como un puente fracturado en tres grietas: tecnológica, pedagógica y salud mental. Cada grieta desarrolla un análisis a partir de información cuantitativa, revelada por la pandemia e interpretada desde el conocimiento pedagógico, histórico y político. El documento no se queda en el análisis, sino que arriesga, en cada grieta, salidas como la pedagogía antiautoritaria, la potenciación de la salud mental en la escuela, así como el replanteamiento del espejismo de la virtualidad.

Palabras clave: Pandemia; pedagogía antiautoritaria; TIC; salud mental; escolaridad.

\section{Abstract}

This document is a reflection about the school using an analogy of a bridge to show how it is cracked in three fissures: technological, pedagogical, mental health. Each of them develops an analysis based on quantitative information revealed by the pandemic and interpreted from pedagogical, historical, and political knowledge. The document doesn't stay in the analysis, but it takes risks, on each crack, to shows potential ways out as the anti-authoritarian pedagogy, mental health potency in the school, and the rethinking of the mirage of virtual reality.

Keywords: Pandemic; antiauthoritarian pedagogy; CIT; mental health; schooling.

\section{Resumo}

O documento é uma reflexão sobre a escola com uma analogia duma ponte fraturada em três fissuras: tecnológica, pedagógica y saude mental. Cada fissura desenvolve uma análise com base na informação quantitativa, auscultada pela pandemia e interpretada desde o conhecimento pedagógico, histórico y político. O documento não fica só na análise, mais arrisca, em cada fissura, saída com a pedagogia antiautoritária, com a potenciação da saúde mental na escola e replantando a miragem da virtualidade.

Palavras-chave: pandemia; pedagogia antiautoritária; TIC; saúde mental; escolaridade. 


\section{Introducción}

F sta reflexión emprende haciendo una analogía $\checkmark$ entre la pandemia, la escuela y un puente. ¿Por qué la analogía? porque "en la analogía tenemos el espacio suficiente para interpretar lo científico y lo poético respetando su especificidad" (Beuchot, 2018, p. 54). Además, esta figura permite encontrar algunos puntos en los que la metonimia, que es el origen de la ciencia, y la metáfora, que es el de la poesía, se toquen sin confusión. De tal guisa que "lo científico pueda interpretarse poéticamente y lo poético científicamente" (Beuchot, 2018, p. 55).

La pandemia es la forastera en esta trilogía de dicciones. De escuelas y puentes tenemos suficiente información, tanto de lo urbano como de lo rural, pero a las pandemias las sabíamos dejadas en el pasado. El COVID-19 abstrae una realidad mórbida, tormentosa, necropolítica y luctuosa que, al desbordar al puente, ha fracturado su superficie, dejándolo a merced de los expertos en la materia para consentir su demolición o reconstrucción, según lo dictaminen los diagnósticos y la ética.

Los expertos, en el caso que nos ocupa, somos las maestras y maestros quienes, a ojo de buen albañil, podemos valorar si esa obra, desbordada por la crisis sanitaria del SARS-CoV-2 y sus mutaciones, se debe demoler o reconstruir. Conocemos los muros de su historia, las arenas del currículo que lo cuajan, la densidad del caudal que pasa por debajo y por las extramuros, el peso psicosocial que soporta la infraestructura, la densidad comunitaria del puente, la longitud de los lingotes de la política que lo deslindan, el engarce de los agentes que le dan raigambre, la tersura pedagógica que lo identifica, la altura sociocultural que caracteriza la obra y la contextura de quienes han sido sus diseñadores, artífices, modeladores y albañiles.

Al revisar al puente, en el oficio de la albañilería, se ponen al descubierto tres profundas grietas que merecen resanes si no se quiere demoler.

\section{La grieta tecnológica}

En un artículo publicado en el crepúsculo matutino del siglo XXI, se lee: "las nuevas tecnologías permitirán a los estudiantes tomar muchas de esas decisiones, acceder a la información que alguna vez estuvo bajo el dominio exclusivo del profesor y navegar por su cuenta sobre la "primera ola y más allá" (Brunner, 1999, p. 28). El autor alude a las escuelas de finales del siglo XX "donde personas revestidas de autoridad decidían qué se iba a enseñar, a qué edad y en qué secuencia" (Brunner, 1999, p. 28), y refiere a los maestros como las personas que tenían el poder de decisión. Pese a que hoy en día continúan teniendo un papel de decisores, las pruebas censales condicionan sus elecciones y los currículos, vulnerando la autonomía institucional: "las libertades de enseñanza, aprendizaje, investigación y cátedra" (Ministerio de Justicia y del Derecho, 1996, p. 23).

Las tecnologías a las que refiere Brunner se circunscriben al computador y específicamente al software

Maestro de la IED Nuevo Horizonte. Trabajador social, Universidad Nacional. ORCID: https://orcid.org/00000002-6872-3593 Correo electrónico: ocavita@yahoo.com 
educacional inteligente, herramientas de la "primera ola", decisivas en el aprendizaje del educando y sustitutos del docente como también lo pretendieron la prensa, radio, cine y televisión. De ahí la aseveración de que "las nuevas tecnologías permitirán a los estudiantes tomar muchas de esas decisiones, acceder a la información que alguna vez estuvo bajo el dominio exclusivo del profesor y navegar por su cuenta..." A ese "futuro-imaginado", como lo apoda el investigador chileno, le pusieron como fecha el 2019, época para la cual se anticipa "el advenimiento de la sociedad PostGutenberg, prácticamente sin impresos, donde la mayor parte del aprendizaje se realiza mediante programas inteligentes que simulan al profesor, el cual ahora desempeña funciones de mentor y consejero más que de fuente de enseñanza y de conocimiento" (Brunner, 1999, p. 29).

El torrente ha descapotado el frágil pañete que recubre al puente y ha auscultado que la sociedad PostGutenberg (sin impresos, con homo conecticus, software, nativos digitales e inteligencia artificial) no tiene agarre en este tiempo ni en el aquí del puente con estos y otros mitos. Los dígitos revelaron que apenas el $4 \%$ de municipios del país tiene buena conectividad, que, en zonas campesinas, tan solo el $9 \%$ de los educandos disponen de computador (Carvajal Rueda, 2020). La misma fuente añade que $2 / 3$ partes de colombianos no tiene conexión a internet fijo, que solo el $45,7 \%$ lo posee en ciudades, el 6,2 \% en el área rural y el mero $17 \%$ tiene acceso a computador y a internet (Carvajal Rueda, 2020).

La Red Latinoamericana de Estudios sobre Trabajo Docente (Red Estrado) en el informe de julio 2021 amplia el espectro en cuanto a uso de herramientas tecnológicas y digitales en 30 departamentos. A noviembre del 2020 declara: 79,1 \% de docentes no tenía formación ni experiencia previa; para el $12 \%$ fue muy difícil el uso; solo $42 \%$ le pareció regularmente fácil. El 92 \% no contó con recursos tecnológicos; 89 \% usó celular, 57 \% computador fijo, $32 \%$ cámara, $31 \%$ micrófono, 45 \% laptop, 12 \% Tablet; $81 \%$ usó banda ancha y 52 \% usó plan de datos móvil. Esta realidad cuestiona el "futuro-imaginado" y todas las olas.

Dentro de este desolador panorama, en el que brillan por su ausencia la cacareada virtualidad y la inoperante educación digitalizada, han sido protagonistas en la educación remota de emergencia, a distancia, el "aprendizaje en casa" y la "Alternancia”, las grabaciones con celulares, el WhatsApp, el e-mail, las fotografías, las guías, los libros, la radio y otros medios tecnológicos menos potentes. En la columna de La Pulla (11 de febrero 2021), con base en fuentes consultadas, se asevera que el $80 \%$ de estudiantes tuvieron que hacer actividades por WhatsApp y fotocopias, entre otros motivos, porque el $66 \%$ de colegios públicos de Bogotá tienen acceso a computadores en casa y solamente 5 de cada 10 tienen buen internet, mientras que, en colegios particulares, el $94 \%$ gozan de buenos equipos y 8 de cada 10 de buena conectividad.

El resultado de la escolaridad a distancia dejó en evidencia que las "Tecnologías de la Idiotización Colectiva", como las denomina un filosofo español (Pigem, 2018), primigenias del homo absortus, fueron inferiores a las tradicionales y vilipendiadas guías impresas, al chat, al correo electrónico, a las grabaciones, al celular e incluso a la radio, a la televisión y no sustituyeron al docente, lo auscultaron. Estos medios han evitado el colapso de la escolarización al lado de unos docentes que enseñan, aconsejan, cuidan y hacen prevención de la COVID-19 a 
millones de educandos y sus familias, disponiendo de su vivienda, equipos, conectividad, tiempo extra, sin soportes y sin los apoyos demandados. La educación virtual aún no se asoma en las aristas del puente y los apologistas e ideólogos que difundieron la sociedad PostGutenberg y le pusieron fecha a la desaparición del maestro y al puente que está salvando a la sociedad y al Estado, hoy, habiendo perdido el valor de la vergüenza del que habla Sabato (Sabato, 2000), exigen a los cuatro vientos el retorno de los educandos al puente sin importan el torrente de la pandemia, so pretexto de que la escuela es segura y de la afectación de la salud mental de los educandos.

Pasados quince meses del cierre de centros educativos queda en evidencia que la escuela es un espacio de socialización insustituible por los artefactos electrónicos. El camino a seguir es fortalecer la estructura original del puente, devolverle la superficie invadida, es decir, las cuatro funciones sociales: custodia, selección del papel social, doctrinaria y la educativa centrada en las habilidades y conocimientos (Reimer, 1973), más la autonomía, los derechos humanos, el cuidado y la formación ciudadana para la cual fue creada por el Estado moderno. Parafraseando a Calvino, sólo después de haber conocido la superficie de las cosas, en este caso la del puente, "se puede uno animar a buscar lo que hay debajo" (Calvino, 1999, p. 5) : un subterfugio de tres obscuras grietas por resanar; lo que anima es que el ser humano, en este caso las maestras y maestros, saben hacer "de los obstáculos nuevos caminos porque a la vida le basta el espacio de una grieta para renacer" (Sabato, 2000, p. 130).

Y no es que lo digital, lo virtual y la internet no sean importantes. Lo son y develan la brecha digital y la desigualdad. Las tecnologías digitales no han sido diseñadas por almas caritativas sino por empresas que buscan jugosos beneficios. Pese a que sus diseñadores "impiden a sus hijos utilizar los móviles y juegos que inventan, precisamente porque saben que generan adicción" (Pigem, 2018, p. 64), y a que los software tienen implicaciones psicológicas en las personas, lo evidenciado con la pandemia es que para los gobernantes colombianos, mucho se ha quedado en el discurso sin compromiso. Las Tecnologías de la Información y Comunicación (TIC) tienen sus propios sentidos en la educación y sus implicaciones en la calidad de vida de las personas, en el proceso escolar y en la cotidianidad.

Para el primer caso, la internet informa, no forma. Internet le dice casi todo al educando, salvo cómo buscar, filtrar, seleccionar, aceptar o rechazar toda la información que proporciona. Un buen profesor:

\begin{abstract}
"puede enseñar a comparar, a verificar y a relacionar sistemáticamente nociones, conceptos, valores y a tener un sentido crítico basado en el conocimiento... Lo que hace que una clase sea una buena clase no es que en ella se aprendan fechas y datos, sino que se establezca un dialogo constante, una confrontación de opiniones, una discusión sobre lo que se aprende en la escuela y lo que ocurre fuera de ella" (Eco, 2016, p. 90).
\end{abstract}

En lo ateniente al segundo caso, está demostrado científicamente que las pantallas afectan la visión de los seres humanos y el Sistema Nervioso Central. Un estudio sobre desarrollo cerebral de 11.000 menores, liderado por el National Institute Health de Estados Unidos, mostró "que aquellos que pasan más de dos horas al día frente a una pantalla de algún dispositivo obtuvieron calificaciones más bajas en el colegio con respecto a otros que habían leí- 
do al menos un libro" (Forero, 2020, p. 110). Según la investigación, la exposición prolongada a pantallas adelgaza la corteza cerebral en los niños, y en el caso de los adultos puede generar depresión. En Colombia, “el 61,9 \% niñas y niños, entre 3 y 4 años, pasa mas tiempo del recomendado frente a las pantallas con implicaciones en el Sistema Nervioso Central, taxativamente en la corteza cerebral" (Caja de Pandora, 2021, p. 267). En lo afín a la salud mental y física de docentes colombianos en 2020, la Red Estrado registra que el 82,6 \% adquirió fatiga visual, $76,6 \%$ estrés, $19,7 \%$, fatiga de voz, $43 \%$, contractura cervical, $61 \%$ dolor de cabeza, 33,9\% pesadez en ambas piernas, 66,3\%, dolores articulares y musculares y $4,2 \%$ ninguna molestia.

Con todo, no se requiere demoler el puente sino reparar la grieta, no meramente limpiarla, para que la escolarización no siga respondiendo a demandas externas del capitalismo cognitivo (afirmado en: estándares, competencias, Derechos Básicos de Aprendizaje, mallas curriculares, evaluaciones censales, rimbombancias en Ciencias naturales, matemáticas, tecnología e ingeniería) ni a trabajos mecánicos, rutinarios y repetitivos, que no enseñan a leer, pensar y convivir en un país que le apuesta a la Escuela Territorio de Paz y a un Proyecto Educativo y Pedagógico Alternativo (Fecode, 2019, p. 25). "Llegó el momento de replantear el sistema y de incorporar un verdadero plan de renovación para garantizar un mínimo de calidad en la educación pública..., expresa Julián de Zubiría" (Carvajal Rueda, 2020, p. 112).

\section{La grieta pedagógica}

La pedagogía es esencial en el funcionamiento del puente, "es el estudio intencionado, sistemático y científico de la educación" (Lemus, 1969, p. 30), es una acción teórico/práctica, mientras que la educación es una actividad práctica no exclusiva de la escuela. El proceso educativo puede desarrollarse de manera artesanal, casi intuitiva, como lo han avanzado los pueblos en el transcurso de su historia. En este sentido, existe un saber implícito, no tematizado, que forma parte de su acervo cultural, y que puede llamarse saber educar. "En la medida en que ese saber se tematiza y se hace explícito, aparece la pedagogía. Hay pedagogía cuando se reflexiona sobre la educación, cuando el saber educar implícito, se convierte en un saber sobre la educación" (Lucio, 1994, p. 42). De ahí que las campañas de radio y televisión, sobre la pandemia, no son pedagógicas, de pronto didácticas, porque no las hacen pedagogos ni hay reflexión sistemática sobre ese saber educar. La pedagogía tiene su estatuto epistemológico y la ejercen pedagogos.

La pedagogía ha sido la infaltable compañera de maestros desde la Paideia, pasando por Platón, Aristóteles, la Didáctica Magna, los colegios-internados de los jesuitas, hasta la actualidad. Sobre lo subscrito, se pueden indicar cuatro grandes momentos históricos: La escuela tradicional, la Tradición renovadora, la Crítica antiautoritaria y la Perspectiva sociopolítica (Palacios, 1984, pp. 13-15). Para Colombia se puede situar ese periplo a finales del siglo XVII con la ilusión del maestro como intelectual con las urgencias lloradas, los silencios obligados, las súplicas por un socorro de limosna y la figura del maestro "idealizada por el Estado” (Martínez B., 1999, p. 152), atravesando por la colonización pedagógica aguijada por las misiones eurocéntricas como la alemana (Helg, 1987, p. 289), la belga, la española y la norteamericana. A su vez, el Movimiento Pedagógico (Gantiva, 1999); el Campo de la Educación en Co- 
lombia (Díaz, 1993); la Educación Popular (Cendales, 2013) y los viajes de la Expedición Pedagógica Nacional (Alvarez, 1999), entre otras expresiones, conforman ese periplo pedagógico.

Con este panorama, el replanteamiento del sistema y la incorporación de un verdadero plan de renovación, no tanto para garantizar un mínimo de calidad de la educación pública, sino para afirmar la estructura del puente desbordado por la pandemia, exigen: el retorno de la pedagogía, el abandono del exilio a donde la expulsó "esa falsa religión centrada en el dios del Mercado" (Pigem, 2018, p. 32) y el "paradigma tecnocrático"; en segundo lugar, que las artes, las letras, la lúdica, la filosofía y las ciencias sociales ocupen el lugar usurpado por los enumerados estándares básicos de competencias, derechos básicos de aprendizaje y las pruebas externas; en tercer lugar, que la pedagogía, las artes, la lúdica y la filosofía, mal llamados "saberes inútiles" por el neoliberalismo, fragüen el fracturado puente, con la consolidación de un proceso escolar en el que la trasmisión fría de conocimientos le posibilite a la terapéutica consolidar una cultura de libertad en estudiantes y profesores, derrumbando las barandas del autoritarismo y atendiendo el tramite de emociones y duelos acaecidos por la borrasca del coronavirus.

El retorno de la pedagogía crítica y terapéutica a la escuela o, si se quiere, a la granja de Ricard, al "viejo huertecito de perfumadas grutas...donde iban los niños a jugar”, parafraseando la parábola de Barba Jacob, es el agua de la acequia, brillante, fresca y pura, que permitirá la oxigenación de la nueva vida escolar, una vida en la que se deje a los niños y niñas desplegar su naturaleza y en la que "la tarea de los padres y educadores consiste en no impedir su desarrollo" (Ferrer Guardia, 1976, p. 120), al ser miembros activos y responsables de una nueva sociedad "que se quiera más a sí misma", igualitaria, libre y justa. La granja es la escuela que en soledad soportó el azote de la pandemia durante muchos meses y al retornar educandos y educadores la desconocen, porque no aparecen las frondas umbrías, ni el naranjero, ni el sauce, ni el palmar, sin más descuellan las ruinas que ha dejado el abandono estatal durante lustros y que en la actualidad pide a gritos la remodelación del puente y la sana cicatrización de las grietas.

El renaciente puente podrá contener en sus quicios al Ángel Novus (Benjamin, 2008 ) con la boca abierta simbolizando la palabra, el grito de libertad y las potencialidades que esta cavidad le facilita al ser humano para articular el lenguaje, la existencia física y mental. Para los educadores la boca se abre y se cierra, en el primer caso, para verbalizar el sentir y pensar como pedagogos; en el segundo, para dejar de repetir lo que las políticas neoliberales quieren que refrende, para no loar al dios del mercado, para exteriorizar su autonomía. Los ojos desencajados reflejan, en su retina, los millones de víctimas, los dolores, secuelas y síndromes circunscritos a la crisis sanitaria del SARS-CoV2, para lo cual se intima la lente de la pedagogía Antiautoritaria.

Las alas tendidas del Angelus Novus, que ondearán en el puente, están reservadas para que educadores y estudiantes inicien un nuevo vuelo en la escolarización, sobre la base de las prácticas reflexionadas que ha dejado la crisis sanitaria. Unas alas que no sigan atosigadas, como decía Zuleta, con esa "ensalada extraordinaria de materias diversas, que el estudiante consume durante seis años, hasta que en el examen de Estado se libera de toda aquella pesada carga de información y confusión” (Suárez, 2020, p. 127) 
El Angel Novus, en este maremagno, en el que lo grande surge de lo pequeño, no se detiene a despertar a los muertos ni a recomponer lo despedazado, porque la grieta pedagógica, al igual que la grieta tecnológica, se pueden resanar, no exige la demolición del puente, haciendo que ese pasado presente de las alas mire hacia el presente futuro, tornando el rostro diametralmente y empujando el empoderamiento de la pedagogía como dominio de maestros; pero no cualquier pedagogía, es la perspectiva sociopolítica y la pedagogía antiautoritaria que hacen de maestros y maestras parteros y parteras del deseo, del conocimiento y del amor por lo que forja, pues la labor no es enseñar la filosofía, sino, "enseñar a filosofar" (Sábato, 2001, p. 92), haciendo uso de la vilipendiada memoria de sangre, que integrada con la memoria vegetal y mineral, potencia el proceso de pensamiento.

Para lograrlo, el educando necesita que los parteros le indiquen que lo memorizado está en un "árbol mental" (Llinás, 1995, p. 56) que puede usar para filosofar, para pensar, para ser solidario, porque en la escuela del "éxito" no se enseña a filosofar, en tanto contraría sus intereses. Tampoco es cualquier educación, se trata de una educación familiar y social "desde la cuna hasta la tumba, inconforme y reflexiva que nos inspire un nuevo modo de pensar y nos incite a descubrir quiénes somos en una sociedad que se quiera más así misma" (García M., 1995, p. 56) $\mathrm{Y}$ en lo afín al aprendizaje, siguiendo a las Contra-pedagogías de la crueldad, "no debemos enseñar a aprender, sino a pensar" (Segato, 2018, p. 137)

La ausencia de las artes y letras, que son también mandadas al exilio por el Science, Technology, Engineering and Mathematics (STEM) y por las políticas educativas ya citadas, hacen de la escolaridad el café con "azúcar, pero sin azúcar” (García M., 1958, p. 40), es decir amarga porque le falta el dulce y ese dulce, acudiendo a otra analogía, se halla, al menos, en tres fuentes. Primero, en el Manual para ser niño, obsequio que el hijo de Aracataca e integrante de la Misión de Sabios hizo a las niñas y niños de Colombia en 1995. "Aspiro a que estas reflexiones sean un manual para que los niños se atrevan a defenderse de los adultos en el aprendizaje de las artes y las letras" expresaba el Nobel de Literatura, aludiendo que no tenían una base científica sino emocional y se fundan en una premisa improbable: "si a un niño se le pone frente a una serie de juguetes diversos, terminará por quedarse con uno de los que le guste más" (García Márquez, 1995, p. 5).

La segunda es el arte y la literatura. Trozos como la peste del olvido e insomnio en Macondo, El amor en los tiempos del cólera, el Ensayo sobre la ceguera, La peste, entre otros, coadyuvan con el sostenimiento del puente resanado. Al descascarillar los resquicios del puente se debe tener en cuenta que: "el descuido y el desprecio de las artes y las humanidades generan un peligro para nuestra calidad de vida y para la salud de nuestras democracias" (Nussbaun, 2010, p. 13). La tercera fuente emana del componente psicosocial donde las emociones, la lúdica, el autocuidado junto con la literatura y el arte, remozan las esquinas del puente, abonando la seguridad de la escuela en la pandemia y luego de ésta.

\section{La grieta de la salud mental}

La grieta tecnológica dejó en la superficie del puente un demarcado agujero sobre las patologías de la realidad virtual, la cibercultura y síndromes como el de burnout o del "trabajador quemado", el Cuerpo fantasma o trastorno de la percepción ocasionado 
por las pantallas, entre otros. En la grieta pedagógica, la reflexión cierra resaltando el valor de las artes y las humanidades, en la calidad de vida y en la salud de las democracias. Enseguida, se podrá dimensionar la problemática de la salud mental y la importancia que tiene para la escuela una postura pedagógica en la que lo terapéutico, el juego y las artes sean el soporte en el resane del puente. Según el Instituto Colombiano de Neurociencias (2020), la "Emergencia sanitaria y su impacto sobre nuestros niños", perturbó al $88 \%$ de educandos entre 4 y 12 años; el $46 \%$ exhibieron problemas de sueño; $36 \%$ contestaba ofensivamente; $31 \%$ frustración; $30 \%$ trastornos de alimentación; $29 \%$ aburrimiento; 26 $\%$ desconcentración; $25 \%$ irritabilidad; $22 \%$ desobediencia; $18 \%$ resistencia a tareas escolares; $18 \%$ más desorden; $42 \%$ presenta problemas con habilidades académicas y una inexacta cantidad despliega desesperanza e ideación suicida.

Antes de la pandemia, la Encuesta Nacional de Salud Mental (ENSM) registraba que el $52 \%$ de los jóvenes, entre 12 y 17 años, ostentaban problemas de ansiedad. Esa franja de población, en la escolarización, se sitúa en la educación Básica y Media. Por su parte, el $80 \%$ de personas de 18 a 44 años manifiesta síntomas depresivos. En ese rango demográfico están los progenitores y familiares de los estudiantes de preescolar a grado once. En cuanto a la población mayor de 45 años, el $72 \%$ de la población presenta entre uno y tres síntomas de depresión (Bienestar Colsanitas, 2018). Aquí encontramos padres de familia y abuelos de los educandos.

La Cooperativa del Magisterio-CODEMA, en una encuesta aplicada en 2019, encontró que del $100 \%$ de encuestados, $87 \%$ consideraba que "en el cumplimiento de sus deberes puede llegar a tener pro- blemas psicológicos”. Apenas el 4,4 \% niega esa posibilidad y el 8,6 \% posee dudas sobre el particular. En lo afín al clima laboral escolar, el 93,5 \% asevera que hay aspectos que lo lesionan y tan solo el 6.5 $\%$ expone que eso no ocurre. Acerca del bienestar en la institución educativa, el 52,1\% revela que se halla muy bien; el 28,2 \% dice sentirse bien y el 19,5 \% declara estar mal (Comité de Salud, 2019, p. 2). Pese a que el $80 \%$ despliega un estado de bienestar, no deja de inquietar que el $20 \%$ presente malestar, porque esa situación recaba la práctica pedagógica, la dinámica familiar, así como la salud física y mental del educador y de los educandos, la cual tiende a acrecentarse.

En el estudio, en proceso de publicación, hecho por el equipo pedagógico y terapéutico Caja de Pandora con docentes y directivos docentes, para indagar en las relaciones de docentes/padres de familia, docentes/docentes, docentes/directivos docentes, docentes/estudiantes, docentes fuera de la institución escolar, docentes/prácticas pedagógicas intracurriculares y en extramuros, se evidencia el interés de docentes y directivos por abordar la salud mental de los escolares desde su formación disciplinar. Igualmente, destapan su preocupación por la ausencia de apoyo estatal y de herramientas para el afrontamiento de las problemáticas y para hacer un trabajo pedagógico integral. La encuesta de Caja de Pandora señala que "el $63 \%$ de los encuestados se interesa y se involucra en las situaciones psicosociales de los estudiantes"; no obstante, este compromiso acarrea conflictos al intentar transformarlos.

Son pocas las investigaciones que sobre salud mental se han hecho en Colombia. A mediados de 1970 y a comienzos de la década de 1980 se hicieron dos macrodiagnósticos, acatando la observancia de 
la Asociación Colombiana de Psiquiatría en la que se advierte: "el problema de la salud mental es uno de los más graves de la salud pública en Colombia" (Rosselli, 1987, p. 298). Los siguientes han tenido al menos tres enfoques: el de 1993, se ocupó de los problemas mentales; los de 1997 y 2003, respectivamente, fueron sobre trastornos mentales y el último, que se acaba de citar (ENSM), articula problemas, trastornos, salud mental, acceso a servicios y medicamentos y valoración de estados de salud. Cobra notabilidad en esta excavación de la grieta, la Historia de la locura en Colombia $(2019,106)$ donde se lee: "luego de entrevistar a mas de cuatro mil pacientes, la organización Médicos Sin Fronteras concluyó que el $67 \%$ sufre trastornos relacionados con el conflicto, $34 \%$ vive con ansiedad, $38 \%$ lidia con la melancolía, millones de víctimas viven entre la desconfianza, la incertidumbre y la incomunicación...". En Montes de María: "90 \% de las participantes en un estudio padece de depresión” (Silva Romero, 2019, p. 106), y más de dos millones de niñas y niños han sido afectados por el conflicto armado.

Volviendo a la situación de la salud mental en la escolaridad, es pertinente señalar que, en "el primer trabajo de investigación que explora el síndrome de desgaste profesional- Burnout en población de docentes de Colombia" (Universidad Nacional de Colombia, 2005, pp. 32-40), llevado a cabo en Medellín, se encontró que el 23,4 \% de la muestra estaba damnificado y un $23,4 \%$ adicional con riesgo de manifestarlo. Luego, dos universidades bogotanas, retomando las recomendaciones de las Universidades Nacional y de Antioquia, llevaron a cabo sendas investigaciones en las que se declara el cansancio emocional, la despersonalización y el agotamiento de docentes.
La investigación "Problemáticas psicosociales de los docentes del Distrito Capital", llevado a cabo por la Universidad de los Andes, surgido con motivo de la implementación del modelo de promoción de estudiantes, halló que el 67,9 \% de los docentes de 25 colegios, en 14 localidades, concuerdan que "las difíciles condiciones de la población estudiantil atendida y la puesta en marcha de políticas educativas ajenas a su decisión no favorecen su bienestar psicosocial" (González Ávila, 2020, p. 101) El estudio: "Prevalencia y características del Síndrome de Agotamiento Profesional (SAP) en docentes de tres colegios públicos de Bogotá", descubrió que "el 43,9\% presentan falta de realización personal; el 49,8 \% despersonalización, por lo menos 15,6 \% tienen SAP con tendencia a subir y 57,4 \% cansancio emocional" (Ospina Pedro, González, 2009).

Dentro de las recomendaciones está "profundizar en el estudio sobre la salud mental de los docentes, estudiar intervenciones eficaces, bien dirigidas, tendientes a promocionar la salud mental y manejar los problemas que existan al respecto" (González Ávila, 2020, p. 103). En esta investigación hecha por la Universidad Javeriana se halló que los docentes orientadores son quienes están llevando la peor parte por la sobrecarga, el acoso laboral, la intensidad en los problemas psicosociales de los estudiantes, y por no saber decirle no a las acciones que no les competen. La Red Estrado señala que las horas de trabajo aumentaron en $94 \%$ en 2020.

El sindicato de Trabajadores de la Educación (ADE), interesado en cavar la grieta de la situación de salud mental de sus asociados, aplicó una encuesta en 19 localidades, en colaboración con el Ministerio de Trabajo y Seguridad Social. El estudio se tropezó 
con docentes estresados, cansados y con baja estima, grietas producidas por el ejercicio de la profesión. El Fondo de Prestaciones Sociales del Magisterio, las Entidades Prestadoras de Salud, algunos medios de comunicación escritos y la revista Educación y Cultura, también han hecho lo suyo. (González, 2020, p. 22-25).

Como se puede apreciar, la grieta de la salud mental es más honda que las otras grietas del puente, entre otras razones, porque las dos anteriores implican inestabilidad emocional, alteraciones mentales y malestar de los docentes. Por lo expuesto, urge la necesidad de aplicarle brea a la grieta pedagógica y la grieta tecnológica, para que la grieta de la salud mental quede bien librada y, de esa manera, el puente minimice los factores de riesgo y más bien potencie los factores protectores. Uno de los factores de riesgo es volver a seguir con las mismas políticas educativas impuestas antes de la pandemia y blindadas con ella; esa actitud socava el puente y ensancha las desigualdades que ha evidenciado la grieta tecnológica. Las grietas no las produce la pandemia, el torrente las pone al descubierto, por eso hablamos más del pasado presente que del presente.

Ponerle la brea de la pedagogía, centrada en la atención propedéutica, terapéutica y psicoterapéutica, es un factor protector del puente, pues los transeúntes que están cruzando por la superficie van cargados de profusas secuelas y dolores germinados por el torrente de la pandemia. Además, al puente le tocará resistir los embates del $26 \%$ de hogares urbanos sin agua y $50 \%$ en lo rural, con el agravante de que en el $6 \%$ urbano es impotable. La deserción escolar de miles de estudiantes es otro coroto que abulta el carruaje que debe soportar el puente. El reclutamiento forzado, que creció en $113 \%$, con respecto a 2019, es un lastre que sigue sobrellevando el puente durante más de sesenta años de guerra; lo mismo que la violencia intrafamiliar y la explotación sexual contra la niñez. La vida por educar y La escuela un territorio que resiste a la guerra, informes que florecieron antes y durante la pandemia, se entregaron a la Jurisdicción Especial de Paz (JEP) y a la Comisión de la Verdad; son documentos que merecen la atención de Colombia para la No Repetición.

Dentro de este paisaje, donde el verde es de todos los colores, retomando a Aurelio Arturo "es bastante malo que un hombre sea ignorante, ya que esto lo priva de la comunicación con el pensamiento con otros hombres. Es peor tal vez que un hombre sea pobre, ya que esto lo condena a una vida de limitación y desvelos en la que no hay tiempo para soñar ni tregua para el agotamiento. Pero con seguridad es mucho peor que no tenga salud, ya que esto le impide luchar contra su pobreza e ignorancia" (Kimble, 1963). Ponerle brea a la grieta de la salud mental, en el puente desbordado por el torrente de la pandemia, es una condición sine qua non para la escolarización inconforme y reflexiva, para que así el puente recobre su fortaleza cicatrizando las grietas: tecnológica, pedagógica y de salud mental, para que niñas, niños, jóvenes, adolescentes y maestros, caminen sobre la superficie del puente hacia la libertad, sin tropezones, sin padres y educadores que impidan su desarrollo, sino que potencien su crecimiento. ‥ 웅 


\section{Referencias}

Alvarez, Alejandro. (1999). Expedición Pedagógica Nacional Pensando el viaje 1. Universidad Pedagógica Nacional.

Benjamin, W. (2008). Ensayos escogidos. Coyoacán S.A.

Beuchot, M. (2018). Lecciones de hermeneútica analógica. Universidad Nacional Autónoma de México.

Bienestar Colsanitas. (2018). Salud mental en Colombia. Bienestar Colsanitas, n. 159, p. 4.

Brunner, J. (1999). Educación: Escenarios de futuro. Nuevas Tecnologías y Sociedad de la Información. Documentos. Ediciones Desde abajo.

Caja de Pandora. (2021). La Caja de Pandora: entre signos de puntuación y síntomas de malestar. Secretaría de Educación de Bogotá DC (Ed.). Pandemia y escuela en Bogotá. Crónicas de maestras y maestros (pp. 244-273). Secretaría de Educación de Bogotá.

Calvino, I. (1999). Las ciudades invisibles. El Mundo Unidad Editorial.

Carvajal Rueda, A. (2020). Nadie se salva solo. Significados de la pandemia que cambió a la humanidad. Paidós.

Cendales, Lola. (2013). Entretejidos de la educación popular en Colombia. Ediciones desde abajo.
Comité de Salud. (2019). La salud mental de los docentes codemados. Web.

Díaz, M. (1993). El campo intelectual de la educación en Colombia. Universidad del Valle.

Eco, U. (2016). De la estupidez a la locura. (Penguin Random House Grupo Editorial.

Fecode. (2019). La escuela territorio de paz. Talleres multiimpresos.

Ferrer Guardia, F. (1976). La escuela moderna. Tusquets Editores.

Forero, E. y otro. (2020). Desafíos de educación en Colombia durante y después de la COVID-19. (Ed.), Nadie se salva solo (pp. 107-122). Paidós.

Gantiva, J. (1999). La reconstrucción del Movimiento Pedagógico. Revista Educación y Cultura, v.50, p. 22.

García M., G. (1958). El coronel no tiene quien le escriba. L. M. Mágica.

García M., G. (1995). La proclama, I. https://doi. org/10.1515/iber.1995.1995.42.30

García Márquez, G. (1995). Manual para ser niño. Ministerio de Educación Nacional

González Ávila, M. P. (2020). Docentes orientadores. Posiciones, disposicionesyproposiciones. (Magisterio, Ed). p.180 
González Blanco, José. (2020). Caja de Pandora: un telar que urde esperanzas.

Helg, A. (1987). La educación en Colombia 19181957. Fondo Editorial CEREC.

Kimble, G. (1963). Tropical África. Twentieth Century Fund.

Lemus, L. A. (1969). Pedagogía. Temas fundamentales. Kapeluz editora S.A.

Llinás, R. (1995). Colombia al filo de la oportunidad. P. de la R.- Colciencias.

Lucio, R. (1994). Educación y enseñanza, pedagogía y didáctica. Aportes, 41. p. 39

Martínez B., Alberto (1999). Maestro, escuela y vida cotidiana en Santafé colonial. Sociedad Colombiana de Pedagogía.

Ministerio de Justicia y del Derecho. (1996). Constitución Política de Colombia. Imprenta Nacional.

Nussbaum, M. (2012). Crear capacidades. Propuesta para el desarrollo humano. (Editorial). https://doi. org/10.2307/j.ctvt7x63g

Nussbaun, M. (2010). Sin fines de lucro. Katz editores. https://doi.org/10.2307/j.ctvndv60c
Ospina Pedro, González, J. y otros. (2009). Salud mental cooperativismo y educación. Editorial Códice Ltda.

Palacios, J. (1984). La cuestión Escolar. E. Laia.

Pigem, J. (2018). Ángeles o robots. Fragmenta editorial.

Reimer, E. (1973). La escuela ha muerto. Barral Editores S.A.

Rosselli, H. (1987). La locura de Epifanio y otros ensayos. Tercer Mundo.

Sabato, E. (2000). La resistencia. Seix Barral.

Sábato, E. (2001). Apologías y rechazos. Grupo Editorial Planeta S.A.

Segato, R. (2018). Contra-pedagogías de la crueldad. Prometeo.

Silva Romero, R. (2019). Historia de la locura en Colombia. Intermedio editores SAS.

Suárez, H. y otros. (2020). Estanislao Zuleta y la educación. La vigencia de su pensamiento. Magisterio Editorial.

Universidad Nacional de Colombia. (2005). Desgaste emocional en docentes oficiales de Medellín. Revista de Salud Pública, 8. 